\title{
Language teachers' perceptions on the use of OER language processing technologies in MALL
}

\section{Pascual Pérez-Paredes, Carlos Ordoñana Guillamón \& Pilar Aguado Jiménez}

To cite this article: Pascual Pérez-Paredes, Carlos Ordoñana Guillamón \& Pilar Aguado Jiménez (2018): Language teachers' perceptions on the use of OER language processing technologies in MALL, Computer Assisted Language Learning, DOI: 10.1080/09588221.2017.1418754

To link to this article: https://doi.org/10.1080/09588221.2017.1418754 


\begin{abstract}
Combined with the ubiquity and constant connectivity of mobile devices, and with innovative approaches such as Data-Driven Learning (DDL), Natural Language Processing Technologies (NLPTs) as Open Educational Resources (OERs) could become a powerful tool for language learning as they promote individual and personalized learning. Using a questionnaire that was answered by language teachers ( $n$ 230) in Spain and the UK, this research explores the extent to which OER NLPTs are currently known and used in adult foreign language learning. Our results suggest that teachers' familiarity and use of OER NLPTs are very low. Although online dictionaries, collocation dictionaries and spell checkers are widely known, NLPTs appear to be generally underused in foreign language teaching. It was found that teachers prefer computer-based environments over mobile devices such as smartphones and tablets and that teachers' qualification determines their familiarity with a wider range of OER NLPTs. This research offers insight into future applications of Language Processing Technologies as OERs in language learning.
\end{abstract}

\title{
KEYWORDS
}

Language learning; teachers' perceptions; OER; MALL; natural language processing technologies; higher education

\section{Introduction}

Mobile devices have become essential for billions of people around the world. The sales and use of mobile devices such as smartphones and tablets have been increasing every year since the beginning of the twenty-first century (Chen \& Denoyelles, 2013; Chen, Yen, \& Chen, 2009), allowing smartphone users both personal satisfaction and social influence (Shin, Shin, Choo, \& Beom, 2011). In 2013, there were more mobile devices than laptops and desktop computers, and smartphones sales surpassed those of regular phones. This popularity and spread can be better understood when one looks at usability factors such as interface simplicity and interactivity (Lee, Moon, Kim, \& Yi, 2015). Mobile 
devices, and in particular smartphones and tablets, have been extremely successful in providing users with 24/7 Internet connectivity and convenience of use (Naismith, 2004), ubiquity (Shin et al., 2011) and a wide variety of multimedia contents, among which there can be found affordable, very often free, quality learning contents (Page, 2014), and, more specifically, language learning materials in the form of Open Educational Resources (OERs).

Thomas and Evans (2014) highlighted the relevance of OERs for language learning and teaching in the context of Web 2.0 services and, among others, user generated content and student production. However, this huge potential remains largely unexplored. Steel (2016) found that Australian university students use mobile devices for speaking, listening, reading, writing, grammar, pronunciation and, lastly, for the learning of language cultural aspects. However, Natural Language Processing Technologies (NLPT) as potential resources for language learning have not been implemented in this same way. Despite the impact of NLPTs, corpora and data-driven learning on language education, no mention was made in Steel (2016) to the use of user-generated resources for the acquisition of languages. Other studies like Chujo and Oghighian (2012), Geluso (2013) or Karras (2016) seem to ignore this potential.

This article explores the role of Mobile Assisted Language Learning (MALL) and teachers' perceptions of Natural Language Processing Technologies (NLPT) as Open Educational Resources (OERs). In particular, it will be discussed how language-related OERs are perceived by the language teaching community in the UK and Spain in terms of knowledge as well as use. Following a definition of OERs as digital resources that can be repurposed for teaching and learning (Thomas \& Evans, 2014), it will be argued that language processing technologies delivered through web services or apps should be considered as valuable OERs in language learning and teaching as they offer the potential to favour active pedagogic approaches, language awareness raising and personalization of the learning experience.

\section{MALL, DDL and language processing technologies as open educational resources in second language education}

Mobile Assisted Language Learning (MALL) takes advantage of the main affordances of mobile devices: ubiquitous learning without the need of a physical permanent cable connection, the ability to exchange information seamlessly with other users and devices, and the availability of educational materials and constant connection between student and teacher (Georgiev, Georgieva, \& Smrikarov, 2004; Kukulska-Hulme, Traxler, \& Pettit, 2007; Kukulska-Hulme, Sharples, Milrad, Arnedillo-Sánchez, \& Vavoula, 2009; Traxler, 2005). MALL may result in improving the learner's ability to retain information, allowing for building knowledge and understanding in different contexts, addressing different learner needs, providing material to students that would not be able to access 
otherwise, or supporting social contact and collaborative learning (KukulskaHulme, 2009; Kukulska-Hulme \& Shield, 2008; Kukulska-Hulme, Traxler, \& Pettit, 2007).

\subsection{Open educational resources as educational materials}

Some digital learning contents can be accessed and used freely as OERs, that is, any type of educational materials (textbooks, lecture notes, assignments, tests, etc.) in the public domain or introduced with an open license which means that anyone can legally and freely copy, use, adapt and re-share them (United Nations Educational, Scientific and Cultural Organization [UNESCO], 2012). These resources can be freely combined, altered, extended or adapted to suit the particular interests of teachers and learners (Rödel, 2013), usually registered under Creative Commons licenses (Beaven, 2013) or repurposed for language learning (Thomas \& Evans, 2014).

In the last decade, the European Union has increased the promotion of OERs since they can facilitate policy dialogue, knowledge sharing and collaboration between states and institutions internationally (Sabadie, Muñoz, Punie, Redecker, \& Vuorikari, 2014). Studies on teachers' perception of OERs show that using them may increase productivity in students through increasing their confidence, interest and satisfaction with the task at hand. Moreover, their use encourages reflective practice for educators. Further studies point out that OERs' awareness is growing (Farrow et al., 2015). OERs were found to shorten the time required to prepare lessons (Wenk, 2010), to reduce teacher isolation and help to expand teachers' roles, inspiring them to find alternative and innovative solutions to the development of their classes, and encouraging reflective practice (Farrow et al., 2015; Petrides, Jimes, Middleton-Detzner, \& Howell, 2010). Bradshaw, Younie, and Jones (2013) stated that the use of OERs can enhance and support teaching and learning practices. Last but not least, OER materials have been found to reduce costs for teachers and students during the course of the academic year (Bliss, Robinson, Hilton, \& Wiley, 2013; Farrow et al., 2015; Wiley, Hilton, Ellington, \& Hall, 2012).

The use of OERs in the context of Higher Education has been studied specifically in the recent years (Adams, Liyanagunawardena, Rassool, \& Williams, 2013). Wenk (2010) stated that for OERs to be useful, they should be easily accessible, their purpose should be clear, and they should be modifiable to suit the teachers' needs. Conole and Alevizou (2010) pointed out several studies looking at how teachers perceive and use OER materials in their teaching habits (Harley et al., 2006; Hylèn, 2006; McAndrew et al., 2009; MIT, 2006, 2009; Petrides, Nguyen, Jimes, \& Karaglani, 2008; Wiley \& Henson, 2006). The main reasons provided as to why teachers looked for OERs were: (a) to expand their courses with new materials; (b) to improve and intellectually expand their teaching habits, and (c) to interact with colleagues with similar interests (Conole \& 
Alevizou, 2010). Other studies later on have shown educators' and students' positive attitudes towards the use of ICTs and OERs in learning and work environments, naming usefulness and ease of use as the main reasons behind it (Edmunds, Thorpe, \& Conole, 2010; Farrow et al., 2015).

The inclusion of OERs in the classroom also presents challenges to overcome. Numerous studies pointed out that there is an overall lack of knowledge in educators regarding OERs and the ethics behind Creative Commons Licenses and restrictions in the publication and sharing of materials. Other issues include the language barrier, the fact that all the sharing and distribution of digital materials is confined within the e-learning institutions, the time and skills needed to fully use the resources and the lack of reward systems to account for the efforts invested in creating and using OERs (Abeywardena, Dhanarajan, \& Chan, 2012; Banzato, 2012; Conole \& Alevizou, 2010; Mishra, Sharma, Sharma, Singh, \& Thakur, 2016; Rolfe, 2012).

According to Littlejohn and Hood (2017), in order for educators to increase the overall use of OERs in the classroom, they need to possess basic knowledge of the technology, to work in a context that supports teaching and learning through OERs and to feel confident with the usage of such tools. It is therefore essential to show them first the value of OERs to later on build up their competence through specialized courses (Yeung, Taylor, Hui, Lam-Chiang, \& Low, 2011), which must show educators what OERs are and how they can be used to address specific needs (Wild, 2012).

Although the efforts for the dissemination of OERs are visible across the EU, they have not yet received the attention needed to draw their fullest potential, and the barriers mentioned above have not been sufficiently addressed. However, studies show there is a growing interest among educators towards knowing and using OERs (Abeywardena et al., 2012; Banzato, 2012; Bliss et al., 2013; Conole \& Alevizou, 2010; Farrow et al., 2015; Masterman, Wild, White, \& Manton, 2011; Murphy \& Wolfenden, 2013; Petrides et al., 2010). OER use and promotion in the EU is still far behind other countries such as the USA or Brazil, with the sole exception of the UK (Sabadie et al., 2014). In Spain, efforts have been focused on higher education and college students, while adult education has not been exploited nearly as much (Romero, Pérez-Mateo, Cabrera, Guitert, \& Maina, 2015). Research shows that there is still a scarcity of information about the factors associated with both the familiarity and the frequency of use of OERs that may contribute to the promotion and the spreading of their implementation across learning contexts.

\subsection{DDL and language processing technologies as open educational resources}

Natural Language Processing (NLP) is the process of understanding, generating, translating and conversing language in written and spoken form automatically 
(Nilsson, 2009). Along with the constant development of new and innovative tools that aim to offer as many services to the consumer as possible, the addition of NLP features has opened a promising avenue for future progress in the field of language learning and linguistics (Granger, Kraif, Ponton, Antoniadis, \& Zampa, 2007). One of the paths within the 'avenue' that the automated processing of natural language has opened has been the ability to use both learners' meta-learning skills and user-generated data in a learning environment. Johns $(1986,1990,1991)$ was one of the first to make use of tools such as concordancers to enhance teaching practices. He encouraged learners to 'research' and draw conclusions based on the linguistic data provided, hence coining the term 'Data-Driven Learning' (DDL), an inductive approach that makes use of attested uses of language as the main source for language learning rather than teachermediated discourse (Karras, 2016; Talai \& Fotovatnia, 2012). Despite the limitations identified in the DDL literature (Heather \& Helt, 2012; Leńko-Szymańska, 2014; Leńko-Szymańska \& Boulton, 2015; Pérez-Paredes, 2010), recent research points to positive appraisal in using linguistic data and DDL in language learning (Ballance, 2017; Charles, 2012, 2014; Chujo \& Oghigian, 2012; Conroy, 2010; Karras, 2016). For instance, Quan (2016) attempted merging DDL with mobile devices by creating a concordance-based app to improve academic English. He concluded that the DDL approach is suitable to merge with Mobile Learning; however, learners found it difficult to find answers on their own from an overload of examples, showing that pedagogical support should never be underestimated when using approaches which require learners interaction with rich data and language complexity (Pérez-Paredes, 2010). Other experiments on subjects learning high-frequency words in English through corpus data through LexTutor software showed that the method improved long-term vocabulary retaining and transferring to new texts (Cobb, 1997, 1999). Other researchers have focused on the application of corpora for language acquisition in the classroom, showing varying degrees of success (Allan, 2006; Boulton, 2010; Kaur \& Hegelheimer, 2005; Lee \& Liou, 2003; Sun \& Wang, 2003; Yoon \& Jo, 2014). Further studies have also looked at how NLP influences the acquisition of the different language skills (Granger et al., 2007; Harbusch, Itsova, Koch, \& Kühner, 2013; Meurers, 2015; Nagata, 2013; Sato, Matsunuma, \& Suzuki, 2013). Given the potential identified in DDL and its accessibility to learners via computers, studies focusing on using language processing technologies and DDL are needed so as to gain a better understanding of how DDL could be implemented in MALL.

Previous research has established NLPTs as resources that can be digitally repurposed for pedagogical means (Thomas \& Evans, 2014). As free and open versions of these tools are found on the Internet, they fit into the definition of OERs (Beaven, 2013; Rödel, 2013; Thomas \& Evans, 2014; UNESCO, 2012). This paper will explore the extent to which OER NLPTs are actually known and used by language teachers across different educational levels in Spain and the 
UK. Such analysis attempts to offer further insight on the possible future applications of the DDL approach in the classroom through the use of OER NLPTs, answering the following research questions:

(1) To what extent are language teachers familiar with the use of mobile devices in the UK and Spain? Do teachers use them for language teaching?

(2) To what extent are language teachers familiar with OER NLPTs in the UK and Spain? Do they use them at all? If so, what resources are most widely used?

\section{Language processing OERs: the teacher perspective}

\subsection{Research methodology}

A survey was used (Owen, 2017) to look at the extent to which L2 teachers are aware and use OER NLPTs and mobile devices in their practice. A questionnaire designed as a result of a literature review of existing resources as well as a discussion and input from experts within the working group was created as a method of data collection. The extensive literature review behind the questionnaire was part of ERASMUS+ TELL-OP, an EU strategic partnership that seeks to promote the use of learner-generated language for learning purposes.

The online questionnaire was developed ad hoc for this study, following standard guidelines for questionnaire creation as a multinational and multilingual survey (de Leeuw, Hox, \& Dillman, 2008; Harkness, 2008). It comprised 21 questions with different response format (yes/no, Likert-type anchored 1-5, and open questions). They were divided into three separate sections: Block A dealt with subject demographics, including gender, age, or experience in the classroom among others (e.g. Please indicate how many years of experience in teaching you have); Block B included questions related to the usage of mobile devices (e.g. Does your institution foster the use of mobile devices (mobile phones, tablets, etc.) in the teaching context?), while Block $\mathrm{C}$ addressed the interest (e.g. 'Are you interested in knowing more about OERs?'), familiarity and frequency of use of language-related OERs in the classroom. The last part of the questionnaire was restricted to those informants who had experience in the use of OERs. The survey was conducted in June 2015 and was delivered online following standard procedure guidelines for Internet-based questionnaires (Manfreda \& Vehovar, 2008). The online platform LimeSurvey was used for its distribution, as it offered a wide variety of tools for creating questionnaires and visualizing the results.

The technologies presented in the questionnaire were selected with the intent of covering as many available types of tools as possible, thus aiming for a high relevance of the survey for the users' needs (de Leeuw et al., 2008). A thorough research was carried out for each of the NLPTs present to ensure that there were 
free and open options to explore, fitting thus the definition of OER. In order to make sure that the respondents were referring to OER NLPTs, examples of freely available tools were provided in each tool's question. The technologies selected addressed different learning skills, such as vocabulary acquisition (online dictionaries, Wordnet), writing skills (spell checkers), reading skills (readability indexes, text summarization tools) and general language awareness tools (Parts-of-Speech taggers). A sample of the survey can be found in http:// www.tellop.eu/wp-content/uploads/2015/09/TELL-OP-Survey-ENG.pdf.

Descriptive statistics were produced based on demographic, teaching and relationship with OER NLPTs data and are presented as percentages or means and standard deviation (SD). Chi-square tests were used for comparison between qualitative variables, and Spearman Rank-order correlations were used for familiarity and frequency of use. The data of the OERs-related scores (familiarity and frequency of use) were not normally distributed as shown by the Kolmogorov-Smirnov Test. Hence, non-parametric Mann-Whitney- $U$ tests, or Kruskal-Wallis when appropriate, were applied to analyse differences between groups. All statistic tests were two-tailed, with significance set at $p<.05$. All statistical analyses were performed with SPSS 22.0 for Windows (SPSS; Chicago, IL, USA).

\subsection{Participants}

The questionnaire was distributed among language teachers through social media and email lists in the areas of applied linguistics, CALL, language teaching and corpus linguistics, following a non-probability sampling, more concretely, a convenience sampling. The dissemination strategy included professional email lists such as EUROCALL, BALL, AESLA, Corpora list, and CALICO as well as contact with Language Schools and Language Academies, Teachers' Unions and Universities through Twitter. For the purpose of this research, we will focus solely on the results collected from teachers based in Spain and the UK (131 from Spain and 99 from UK).

Table 1 describes the main characteristics of the sample collected. Participants were mostly women aged between 36 and 55; the participants' backgrounds were mostly in Modern Languages, Applied Linguistics, Education and Language and Literature, and Higher or Secondary education were the most common institutions represented in the survey results. The qualification for educators based in Spain was mostly $\mathrm{PhD}$ (38.93\%), while the UK-based participants were BA and MA (39.39\% in both cases). Most of the teachers in Spain had between 11-15 years of experience in teaching (29.01\%), while most of the UK-based subjects had 16-20 (27.27\%). Almost three out of four participants from Spain taught English as a foreign language while 'Other languages' and French were most common in the UK. 
Table 1. Characteristics of the participants.

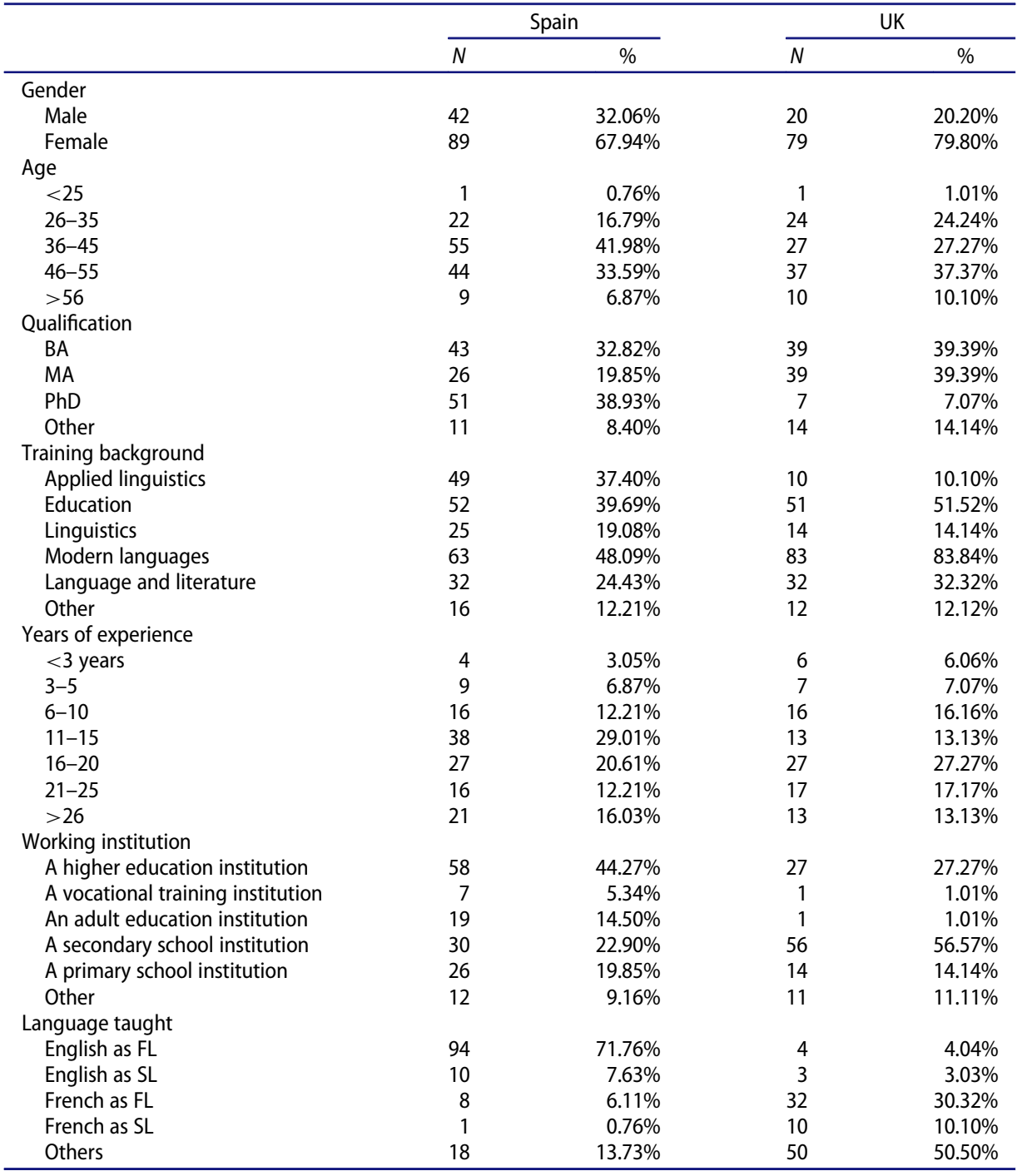

\section{Results}

\subsection{RQ 1. Technology and mobile devices in the classroom}

Most of the language teachers surveyed claimed that their institution provided them with WiFi connection (Spain: 83.97\%; UK: 87.88\%). Although they estimated their own computer skills as medium-high (41.22\% scored 3-4 in a scale from 1 to 5 , where 5 would be 'expert computer skills'), some differences were observed between countries, Spain-based educators overall claiming to be more skilled than UK-based teachers. Institutions fostering the use of mobile devices are reported more frequently in the UK (68.69\%) than in Spain $(51.15 \%)\left(\chi^{2}=7.16 ; p=.005\right)$; and a similar pattern is found for lack of training 


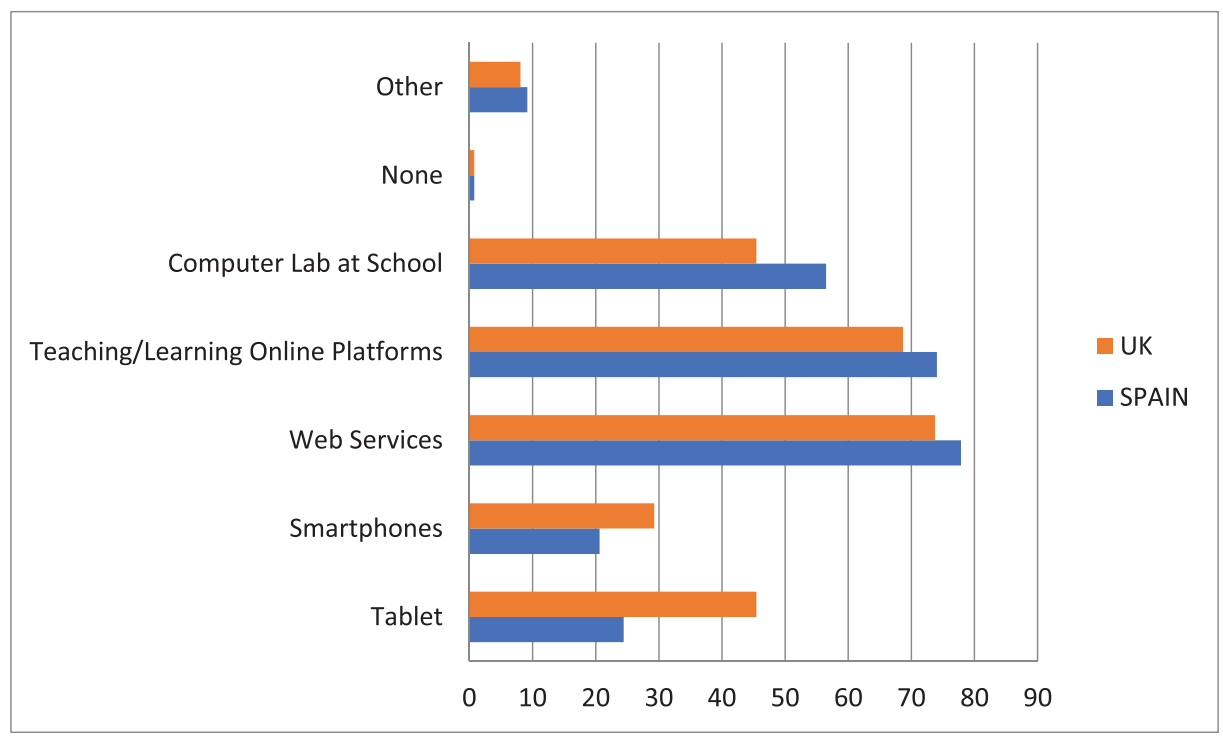

Figure 1. Frequency of use of different types of devices in the classroom.

in the use of mobile devices (Spain: 76.34\% vs. UK: 65.66\%), although not reaching significance $\left(\chi^{2}=3.17 ; p=.052\right)$.

Figure 1 shows the frequency of use of different types of devices in the subjects' language teaching. The general response leant towards web services and teaching/learning online platforms (Between 65\% and $80 \%$ in both countries), while smartphones were the least used. Main between-country difference shows that UK respondents appear to use tablets more frequently (UK: 45.45\%; Spain: $\left.24.43 \% ; \chi^{2}=11.19 ; p=.001\right)$. Additionally, although not statistically significant, a higher percentage of UK teachers use smartphones (UK: 29.29\%; Spain: $20.61 \%$ ), while Spanish teachers rely more frequently on computer labs at school (Spain: 56.49\%; UK: 45.45\%). When asked for the frequency with which teachers used mobile devices in the classroom, the highest percentage answered 'never' (Spain: 25.19\%; UK: 28.3\%), followed by 'a few times a year' (Spain: $22.14 \%$; UK: $25.3 \%$ ); while about one third said to use them at least on a weekly basis (Spain: 35.1\%; UK: 32.3\%).

\section{2. $R Q$ 2. Natural language processing technologies as open educational resources}

When teachers were asked whether they were familiar with OERs, significant between-country differences were found $\left(\chi^{2}=23.59 ; p<.001\right)$. In Spain, most of the respondents (41.98\%) reported to be familiar with OERs, $22.14 \%$ had heard of them but never used them, while $35.88 \%$ did not know anything about OERs. The results collected from UK-based educators show that fewer subjects claimed to be familiar with OERs $(24.24 \%)$ or had 'heard of them but never 
used them' $(8.08 \%)$, while $67.68 \%$ claimed not knowing about them. However, interest in knowing more about OERs was equally widespread among teachers in both countries (Spain: $82.44 \%$ vs. UK: $82.83 \%$ ).

Among those who confirmed that they were familiar with OERs (84 and 31 subjects in Spain and UK, respectively), there were no apparent betweencountry differences. Most of the sample never use OERs in the context of language teaching or only use them a few times a year (Spain: 60.71\%; UK: $56.26 \%$ ) (Table 2).

In the following items, a set of various Natural Language Processing Technologies as Open Educational Resources was presented to the informants for them to indicate the extent to which they were familiar with and how frequently they used each one.

Figure 2 shows the mean scores for the familiarity with OER NLPTs and frequency of use respectively. The OER NLPTs teachers are most familiar with are Online Collocation Dictionaries, Spell Checkers and Language learning apps. However, only the first shares the same ranking in both familiarity and frequency of use. On the opposite side, Vocabulary Profiling, Text density/readability index and automated POS tagging are the least known in terms of both familiarity and frequency of use. Teachers' familiarity levels were found to be higher than their frequency of use for all the NLPTs. As expected, Spearman Rank-order Correlations between familiarity and use were found to be significant $(p<.001)$ for every OER in the questionnaire. That is, teachers' familiarity level is significantly associated with how frequently they use a certain NLPT as OER.

Significant between-country differences were found in the familiarity with online collocation dictionaries or databases $(U: 655.5 ; p<.001)$, text summarization ( $U: 1016 ; p=.016)$, L1 corpora $(U: 987 ; p=.021)$, specialized corpora $(U: 998 ; p<.023)$, and learner corpora $(U: 1039 ; p=.042)$. Only online collocation dictionaries $(U: 932.5 ; p=.009)$ was significantly different for frequency of use though. In all cases, teachers based in Spain showed higher means for both familiarity and use than those from UK.

Training in the use of mobile devices ( $U: 3799 ; p<.001$ ), and fostering their use in the classroom $(U: 3835 ; p<.001)$ appears to have a relevant association with the frequency of use of such devices but little impact on familiarity or

Table 2. Results for teachers' frequency of use of OERs.

\begin{tabular}{lcc}
\hline & \multicolumn{2}{c}{$\begin{array}{c}\text { How often do you use OERs in } \\
\text { the context of language teaching? }\end{array}$} \\
\cline { 2 - 3 } & Spain & UK \\
\hline Never & $28.57 \%$ & $34.38 \%$ \\
A few times a year & $32.14 \%$ & $21.88 \%$ \\
Monthly & $13.10 \%$ & $15.62 \%$ \\
On a weekly basis & $19.05 \%$ & $21.88 \%$ \\
Everyday & $7.14 \%$ & $6.25 \%$ \\
\hline
\end{tabular}




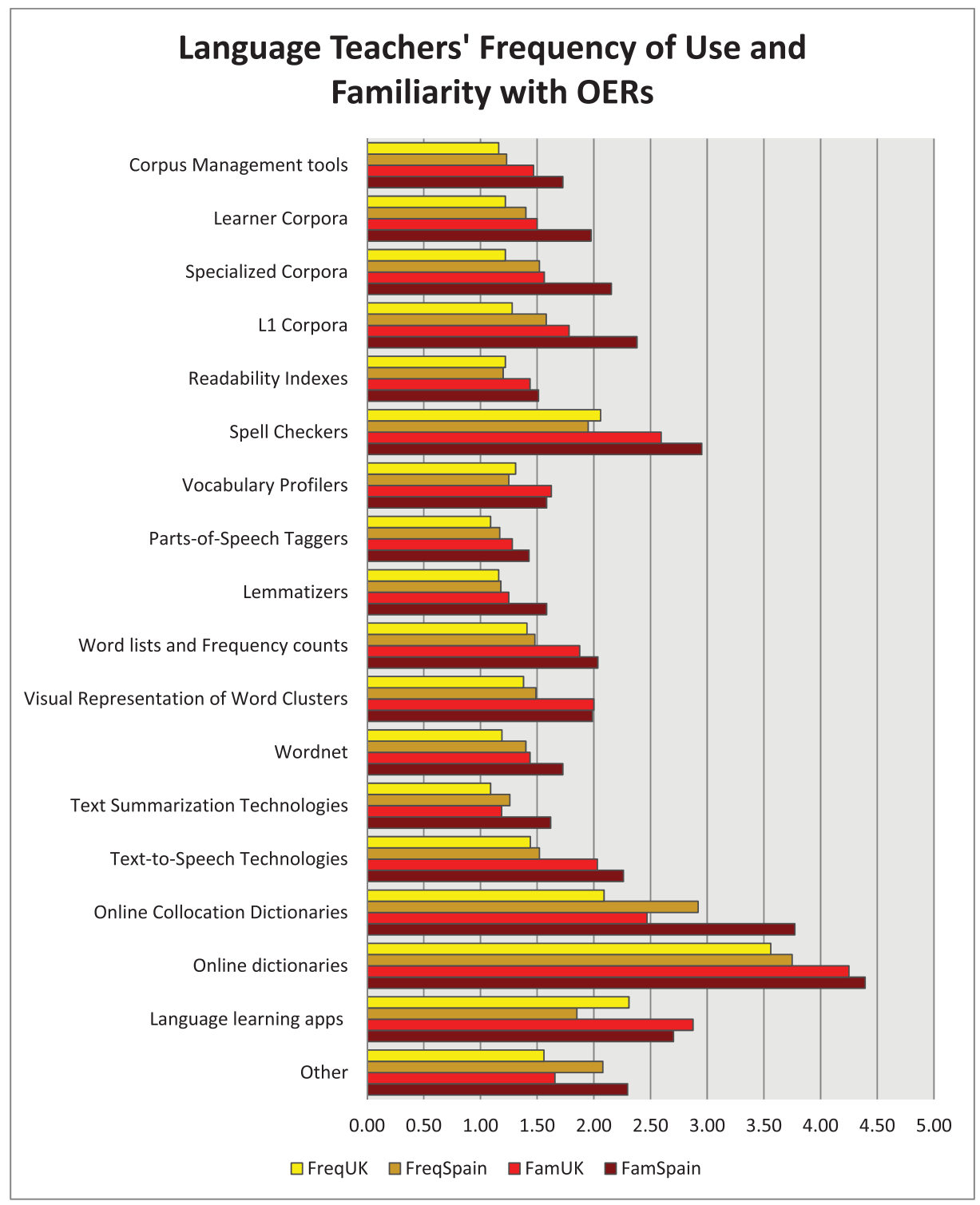

Figure 2. Teachers' familiarity and frequency with OERs.

frequency of use of OER NLPTs. Only the frequency of use of L1 corpora is significantly associated $(U: 1157 ; p=.035)$ to training. When institutions foster the use of mobile devices in the teaching context, teachers use such devices more frequently ( $U: 3835 ; p<.001$ ). However, when analysing specific OERs, associations are scarce, and fostering significantly increases only familiarity with online dictionaries ( $U: 1331.5 ; p=.031$ ), and frequency of use of $L 1$ corpora ( $U: 1392$; $p=.046)$.

Institutional affiliation shows significant differences in the familiarity with OER NLPTs (with the exception of Text-to-Speech technologies, Language 
learning Apps, Online Dictionaries, Visual representation of Word Clusters and Spell Checkers), the most significant being Readabillity Indexes and all corporarelated tools. This association does not extend to frequency of use except for $L 1$ corpora and Specialized corpora. However, it must be noted that although the difference leans towards higher scores for HE teachers, the overall scores for both familiarity and frequency of use are still very low (see Appendices 1 and 2).

The qualification of the teachers surveyed suggests that the higher their qualification, the more likely the subject is of being familiar with a certain tool (see Table 2). The biggest difference can be found in all corpora tools, TTS, Lemmatizers and Vocabulary Profiling tools. Subjects with a $\mathrm{PhD}$ present overall higher scores for familiarity than MA subjects, which in turn present higher scores than BA subjects, although, again, the differences were mainly non-significant for frequency of use. Frequency of use of mobile devices shows no difference regarding qualification or workplace, as with familiarity and use of language learning apps or spell checkers.

Other variables like gender, age group or years of teaching experience showed no association with either familiarity or frequency of use in any of the NLPTs studied. The only significant association was found between being male and familiarity with language learning apps ( $U: 970.5 ; p=.005)$.

\section{Discussion}

Our results offer a snapshot of how mobile devices, MALL and OER NLPTs are perceived and used by language teachers in the UK and Spain. The fact that the vast majority of the institutions offer connection to the Internet for teachers suggests that, presumably, most of them are able to access the resources during lessons at any time. It was also found that the promotion of the use of mobile devices in the classroom is not widespread, with half of the respondents claiming that their institutions foster the inclusion of mobile devices in the classroom. This finding suggests that institutions are gradually working towards the integration of mobile devices in official curricula. However, most of the subjects claimed not having received any training whatsoever in how to do this. The UK seems to be ahead of Spain in terms of both encouraging and offering training in the use of mobile devices. Among the devices that teachers utilize, smartphones and tablets appear to be the least used in contrast with computer labs, teaching/learning online platforms or web services, which is consistent with the widespread lack of training in mobile devices use. In terms of frequency of use of mobile devices, the general tendency among those surveyed leans towards a low usage of mobile devices in the classroom, with almost half of the respondents claiming not to use them more than a few times a year. Although institutions in the UK seem to favour the inclusion of mobile devices in the classroom, Spain-based teachers apparently make use of mobile devices more frequently than their UK-based counterparts. However, when the results from both 
countries were compared, significant differences could not be found that would suggest a higher use of mobile devices either in Spain or the UK.

As for OERs, most of the respondents claimed not knowing much about them, but the vast majority (Spain: 82.44\%; UK: $82.83 \%$ ) showed interest in acquiring more knowledge on OERs. Our results support the claim that it is necessary to have acquired a basic knowledge about OER NLPTs and their capabilities in order to build up and spread their usage (Littlejohn \& Hood, 2017; Wild, 2012; Yeung et al., 2011). The generally low rate of familiarity and frequency of use suggests that there currently exists a widespread lack of knowledge about OER NLPTs and what they can be used for (Abeywardena et al., 2012; Banzato, 2012; Conole \& Alevizou, 2010; Mishra et al., 2016; Rolfe, 2012), which seems to indicate that more awareness initiatives are needed to increase their potential use (Kukulska-Hulme, 2016) or, alternatively, that the existing ones are not being effective enough to create a solid base of knowledge that supports the increasing implementation of language-related NLPTs in the classroom. The results also align with previous surveys on educators (Farrow et al., 2015) which point out the low usage of OERs as well as the positive attitudes towards its use in the teaching context.

Focusing on the individual OER NLPTs, Online Dictionaries, Collocation Dictionaries and Spell Checkers were the most widely known, whilst resources such as Lemmatizers, POS Taggers, Vocabulary Profiling tools and Readability Indexes were the least known among the language teachers surveyed. The main purposes for using tools such as Online Dictionaries or Spell Checkers seem to be the improvement of lexical knowledge and writing skills, as found in studies of language learning and teaching in mobile environments (Charles, 2012, 2014; Chujo \& Oghigian, 2012; Geluso, 2013; Karras, 2016; Ma, 2016; Quan, 2016). However, most MALL studies have focused on vocabulary learning using memory-based, repetition-based or multiple-choice exercises, setting them apart from other vocabulary learning and writing tools such as Vocabulary Profilers, Wordnet or different types of corpora, which, in the context of DDL, could offer a more learner-centred experience and individualized and personalized learning. These tools also require a steeper learning curve to be used properly, and most of them have received mobile support only quite recently. This could explain the differences in familiarity among vocabulary learning and writing skills-oriented tools whereas Online Dictionaries, Collocation Dictionaries and Spell Checkers are more widely known. This finding suggests that, given the teachers' limited knowledge, there is plenty of room for the dissemination of OER NLPTs that promote language learning experiences that are (1) geared towards a more integrated view of language learning skills and (2) favour more personalized learner experiences. Regarding the remaining types of tools, studies such as Steel (2016) and Ma (2016) suggest that learners also seem to favour vocabulary learning over other language skills, using smartphones to browse web contents and use dictionary apps, using marginally language learning apps and vocabulary lists. 
Ballance (2017) has suggested that the limited uptake of concordancers in mainstream language learning can be explained by factors such as the difficulty in their use, the insufficient existing training to take advantage of their capabilities and the limited access to the resources. Tools that can be perceived as more sophisticated such as Lemmatizers, Readability Indexes or POS taggers are more likely to see their rate of use significantly decreased among language teachers who are not actively pursuing the design and writing of materials.

Previous research has showed that for OER NLPTs to expand their reach, they need to be accessible and easy to use (Wenk, 2010). Our informants' habits seem to confirm these statements as, for example, dictionaries and spell checkers offer quick, direct and concise results both on desktop and mobile devices, are mostly freely accessible and are easy to use. This paper argues that the use of OER NLPTs that require some degree of sophistication and training need to be adapted and presented in ways that contribute to learning experiences that reinforce the pedagogical contributions while they decrease the challenges and obstacles involved in using OERs which do not necessarily present pedagogical user interfaces (Pérez-Paredes, 2010). As a matter of fact, accessibility and familiarity are crucial factors. Conroy (2010) experimented with students using Google search for concordancing, with the results stating that they managed better and showed more improvement than when they used a proper concordancing tool. Familiarity and ease of use were said to be crucial in explaining such improvement in performance. Geluso (2013) also studied the use of Google for language learning purposes, showing significant increase in the naturalness of the subjects' writing, while Pérez-Paredes, Sánchez-Tornel, and Calero (2012) found that even after dedicated corpus training, students' queries on the British National Corpus (BNC) resembled their query behaviour on Google.

There are, however, other factors that may influence the use of many of these resources. Our results showed that teachers' qualification plays a significant role in the adoption of NLPTs as OER, as PhDs tended to be more familiar with tools that might be considered 'advanced' such as different types of corpora, POS taggers or Lemmatizers than subjects with BAs or MAs. Our results show that mobile devices appear to be underused in foreign language teaching. The teachers surveyed tend to use computer-based environments (online platforms, computer labs or web services) rather than taking advantage of mobile devices such as smartphones and tablets. Although some researchers have stated that mobile apps were paving the ground for innovative practices in mobile learning (Godwin-Jones, 2008), early studies in the performance of learning activities on smartphones suggested a low usage of mobile devices with respect to computers (Stockwell, 2010), mainly influenced by the technological constraints of the moment in which smartphones had recently become mainstream and tablets did not exist yet. More recent studies, however, point out to users perceiving language learning apps as limited in pedagogical variance and immature (Steel, 2016). This suggests that more studies that focus on pedagogical affordances 
rather than technology are needed in CALL if one is to transfer some of the affordances of desktop computers (Pérez-Paredes, 2010) to mobile devices.

OERs have been found to contribute to improving language learning and teaching in multiple ways (Bliss et al., 2013; Bradshaw et al., 2013; Farrow et al., 2015; Sabadie et al., 2014; Wenk, 2010; Wiley et al., 2012). The continuous use of these resources contributes to the personalization of the learning experience, creating a new skillset in data literacy and allowing for a growing role for multimodality in meaning-making (Pegrum, 2016). OERs also help develop contextaware language learning through MALL (Traxler \& Kukulska-Hulme, 2016) and promote the individualization and personalization of the learning process (Kukulska-Hulme, 2016). Our results suggest that both lack of teachers' familiarity and use of such resources may be depriving language learners of opportunities to further enhance their learning experiences in MALL contexts. Although OERs have been established lately as highly beneficial, the inclusion of NLPT as OERs in the classroom comes with a series of challenges that must first be faced: (i) This study has focused on NLPTs that are freely available; (ii) Accessibility and ease of use have been named numerous times as crucial factors in the potential usability of a resource (Conroy, 2010; Geluso, 2013), therefore those lesserused tools need more user-friendly interfaces to increase their use; (iii) The fact that technology and pedagogic practices evolve at different speeds must be considered as well, suggesting a longer effort in updating the studies being carried out and a constant online support when developing tools that enhance teaching and learning.

The general attitude shown towards the use of OER NLPTs is positive, aligning with the findings in the literature (Conole \& Alevizou, 2010; Edmunds et al., 2010; Farrow et al., 2015), and the vast majority of the teachers showed interest in knowing more about OERs. This suggests that further attempts on promoting the use of OER NLPTs, such as designing training programs directed to educate teachers on the proper use of OER NLPTs, would be well received and therefore more likely to succeed. The constant development of technology, the evolution of pedagogic practices as well as societal changes have made digital competence a key part of contemporary education. Given the low levels of use of mobile devices and dedicated NLPTs in the language classroom both in the UK and Spain, it may be necessary to create conversations between teachers and learners, among learners and between learners and technology so as to make knowledge and reasoning more explicit, thus promoting more diverse learning opportunities. It seems plausible to think that language teachers in other European countries may present similar familiarity rates with the range of OERs discussed in our research, which suggests that the findings in this paper may attract the interest of language professionals beyond the UK and Spain.

By using NLPTs and mobile devices, learning is likely to become more closely intertwined with the learners' personal daily experiences as OERs allow for learning to take place outside the classroom, facilitating the development of 
user-generated content. The use of OER NLPTs and apps through mobile devices is part of a teaching strategy that considers, and most likely changes, how, when and where teachers and learners interact with each other and with other means of personalization of the learning experience, allowing as well for the exploration of authentic language problems and challenges that may arise in the learner's everyday life.

\section{Conclusion}

This study has offered further insight into how mobile devices and NLPTs are perceived and used by language teachers in Spain and the UK. Our findings are of importance for language professionals, material designers and CALL researchers interested in implementing MALL that makes use of language-processing-related resources. This article argues that OER NLPTs through mobile devices, if considered as valuable resources in the current landscape of language learning and teaching, may play an important role in shifting pedagogic approaches towards more learner-centred models, in raising learners' language awareness and in promoting personalized learning experiences.

There are limitations in our research that must be taken into account. Although our sampling strategy has been widely adopted in similar types of research, a study with a broader number of subjects would yield more definite conclusions. The use of different professional email lists may have arguably provided us with a different sample, which may have potentially affected the nature of our discussion. Similarly, a questionnaire of learners' use of language-related OERs may have provided us with a more complete picture of the language learning landscape.

This research has unveiled a low rate of both familiarity and use of mobile devices and OERs, among the language teachers in the UK and Spain that completed our questionnaire. This paper also tried to shed light into the challenges and opportunities that the use of NLPTs may create in the context of mobile language teaching and learning. The fact that educators are not sufficiently aware of the possibilities of using OER NLPTs may be depriving language learner of chances to engage with learning opportunities that are not promoted in commercial MALL. It appears that the efforts to promote the use of mobile devices and general-purpose language learning OERs in the classroom have not been sufficient or effective enough. Further research may focus on the pedagogical implications of the inclusion of OER NLPTs in such contexts.

\section{Disclosure statement}

No potential conflict of interest was reported by the authors.

\section{Funding}

This work was supported by the EU - ERASMUS+ [grant number 2014-1-ES01-KA203004782]. 


\section{References}

Abeywardena, I. S., Dhanarajan, G., \& Chan, C. S. (2012, September). Searching and locating

OE R : Barriers to the wider adoption of OER for teaching in Asia. Proceedings of the regional symposium on open educational resources: An Asian perspective on policies and practice, Penang, Malaysia: Regional Symposium on Open Educational Resources: An Asian Perspective on Policies and practice.

Adams, A., Liyanagunawardena, T., Rassool, N., \& Williams, S. (2013). Use of open educational resources in higher education. British Journal of Educational Technology, 44, 149150. doi:https://doi.org/10.1111/bjet.12014

Allan, R. (2006). Data-driven learning and vocabulary: Investigating the use of concordan ces with advanced learners of English (Centre for language and communication studies occasional paper No. 66). Dublin: Trinity College Dublin.

Ballance, O. (2017). Pedagogical models of concordance use: Correlations between concordance user preferences. Computer Assisted Language Learning, 30, 259-283.

Banzato, M. (2012, September). Barriers to teacher educators seeking, creating and sharing open educational resources: An empirical study of the use of OER in education in Italy. Proceedings of the 2012 15th international conference on interactive collaborative learning (ICL). Villach, Austria: IEEE. doi:https://doi.org/10.1109/icl.2012.6402105

Beaven, T. (2013). Use and reuse of OER: Professional conversations with language teachers. Journal of e-Learning and Knowledge Society, 9, 59-71.

Bliss, T., Robinson, T., Hilton, J., \& Wiley, D. (2013). An OER COUP: College teacher and student perceptions of open educational resources. Journal of Interactive Media in Education, $1,1-25$.

Boulton, A. (2010). Data-driven learning: Taking the computer out of the equation. Language Learning, 60, 534-572. 
Bradshaw, P., Younie, S., \& Jones, S. (2013). Open education resources and higher education academic practice. Campus-Wide Info Systems, 30, 186-193. doi:https://doi.org/10.1108/ 10650741311330366

Charles, M. (2012). Proper vocabulary and juicy collocations: EAP students evaluate do-ityourself corpus-building. English for Specific Purposes, 31, 93-102.

Charles, M. (2014). Getting the corpus habit: EAP students' long-term use of personal corpora. English for Specific Purposes, 35, 30-40.

Chen, B., \& Denoyelles, A. (2013). Exploring students' mobile learning practices in higher education. Educause Review. Retrieved fromhttp://www.educause.edu/ero/article/explor ing-students-mobile-learning-practices-higher-education

Chen, J., Yen, D., \& Chen, K. (2009). The acceptance and diffusion of the innovative smart phone use: A case study of a delivery service company in logistics. Information \& Management, 46, 241-248. doi:https://doi.org/10.1016/j.im.2009.03.001

Chujo, K., \& Oghighian, K. (2012). DDL for EFL beginners: A report on student gains and views on paper-based concordancing and the role of L1. In J. Thomas \& A. Boulton (Eds.), Input, process and product: Developments in teaching and language corpora (pp. 170-183). Brno: Masaryk University Press.

Cobb, T. (1997). Is there any measurable learning from hands-on concordancing ? System, 25, 301-315.

Cobb, T. (1999). Applying constructivism: A test for the learner-as-scientist. Educational Technology Research \& Development, 47, 15-33.

Conole, G., \& Alevizou, P. (2010). A literature review of the use of Web 2.0 tools in higher education. Retrieved 30 December, 2016, fromhttps://core.ac.uk/download/pdf/5162.pdf

Conroy, M. A. (2010). Internet tools for language learning: University students taking control of their writing. Australasian Journal of Educational Technology, 26, 861-882.

de Leeuw, E. D., Hox, J. J., \& Dillman, D. A. (2008). The cornerstones of survey research. In E. D. de Leeuw, J. J. Hox, \& D. A. Dillman (Eds.), International handbook of survey methodology, (pp. 1-17). Abingdon: Routledge. doi:https://doi.org/10.4324/9780203843123.ch1.

Edmunds, R., Thorpe, M., \& Conole, G. (2010). Student attitudes towards and use of ICT in course study, work and social activity: A technology acceptance model approach. British Journal of Educational Technology, 43, 71-84. doi:https://doi.org/10.1111/j.14678535.2010.01142.x

Farrow, R., Pitt, R., de los Arcos, B., Perryman, L., Weller, M., \& McAndrew, P. (2015). Impact of OER use on teaching and learning: Data from OER Research Hub (2013-2014). British Journal of Educational Technology, 46, 972-976. doi:https://doi.org/10.1111/bjet.12310

Geluso, J. (2013). Phraseology and frequency of occurrence on the web: Native speakers' perceptions of Google-informed second language writing. Computer Assisted Language Learning, 26, 144-157.

Georgiev, T., Georgieva, E., \& Smrikarov, A. (2004, June). m-learning: a new stage of m-learning. Proceedings of the 5th international conference on computer systems and technologies CompSysTech '04, doi: 10.1145/1050330.1050437. Rousse, Bulgaria.

Godwin-Jones, R. (2008). Emerging technologies. Web-writing 2.0: Enabling, documenting, and assessing writing online. Language Learning \& Technology, 12, 8-13.

Granger, S., Kraif, O., Ponton, C., Antoniadis, G., \& Zampa, V. (2007). Integrating learner corpora and natural language processing: A crucial step towards reconciling technological sophistication and pedagogical effectiveness. ReCALL, 19, 252-268. doi:10.1017/ S0958344007000237

Harbusch, K., Itsova, G., Koch, U., \& Kühner, C. (2013). Computing accurate grammatical feedback in a virtual writing conference for German-speaking elementary-school children: An approach based on natural language generation. CALICO Journal, 26, 626-643. 
Retrieved 3 June, 2017, fromhttps://journals.equinoxpub.com/index.php/CALICO/article/ view/23064

Harkness, J. A., 2008, Comparative survey research : goal and challenges. In E. D. de Leeuw, J. J. Hox, \& D. A. Dillman (Eds.), International handbook of survey methodology, (pp. 5677), Abingdon: Routledge. doi:https://doi.org/10.4324/9780203843123.ch4.

Harley, D., Henke, J., Lawrence, S., Miller, I., Perciali, I., \& Nasatir, D. (2006). Use and users of digital resources: A focus on undergraduate education in the humanities and social sciences. Berkeley, CA: Center for Studies in Higher Education, UC Berkeley. Retrieved fromhttp://cshe.berkeley.edu/research/digitalresourcestudy/report/digitalresourcestudy_fi nal_report_text.pdf

Heather, J., \& Helt, M. (2012). Evaluating corpus literacy training for pre-service language teachers: Six case studies. Journal of Technology and Teacher Education, 20, 415-440.

Hylén, J. (2006). Open educational resources: Opportunities and challenges. Paris, France: OECD's Centre for Educational Research and Innovation. Retrieved from http://www. oecd.org/dataoecd/5/47/37351085.pdf

Johns, T. (1986). Micro-concord: A language learner's research tool. System, 14, 151-162.

Johns, T. (1990). From printout to handout: Grammar and vocabulary teaching in the context of data-driven learning. CALL Austria, 10, 14-34.

Johns, T. (1991). Should you be persuaded. Two samples of data-driven learning materials. Classroom Concordancing: ELR Journal, 4, 1-16.

Karras, J. (2016). The effects of data-driven learning upon vocabulary acquisition for secondary international school students in Vietnam. ReCALL, 28, 166-186. doi:10.1017/ S0958344015000154

Kaur, J., \& Hegelheimer, V. (2005). ESL students' use of concordance in the transfer of academic word knowledge: An exploratory study. Computer Assisted Language Learning, 18, 287-310.

Kukulska-Hulme, A. (2009). Will mobile learning change language learning ? ReCALL, 21, 157-165. doi:https://doi.org/10.1017/s0958344009000202

Kukulska-Hulme, A. (2016). Personalization of language learning through mobile technologies. Cambridge, UK: Cambridge University Press.

Kukulska-Hulme, A., Sharples, M., Milrad, M., Arnedillo-Sánchez, I., \& Vavoula, G. (2009). Innovation in mobile learning: A European perspective. International Journal of Mobile and Blended Learning, 1, 13-35.

Kukulska-Hulme, A., \& Shield, L. (2008). An overview of mobile assisted language learning: From content delivery to supported collaboration and interaction. ReCALL, 20, 271-289. doi:https://doi.org/10.1017/s0958344008000335

Kukulska-Hulme, A., Traxler, J., \& Pettit, J. (2007). Designed and user-generated activity in the mobile age. Journal of Learning Design, 2(1), 52-65. Retrieved June 30, 2008, fromhttp://www.jld.qut.edu.au/

Lee, C.-Y., \& Liou, H.-C. (2003). A study of using web concordancing for English vocabulary learning in a Taiwanese high school context. English Teaching and Learning, 27, 35-56.

Lee, D., Moon, J., Kim, Y., \& Yi, M. (2015). Antecedents and consequences of mobile phone usability: Linking simplicity and interactivity to satisfaction, trust, and brand loyalty. Information \& Management, 52, 295-304. doi:https://doi.org/10.1016/j.im.2014.12.001

Leńko-Szymańska, A. (2014). Is this enough? A qualitative evaluation of the effectiveness of a teacher-training course on the use of corpora in language education. ReCALL, 26(2), 260-278. doi:10.1017/S095834401400010X

Leńko-Szymańska, A., \& Boulton, A. (2015). Multiple affordances of language corpora for data-driven learning (1st ed.). Amsterdam: John Benjamins Publishing Company. 
Littlejohn, A., \& Hood, N. (2017). How educators build knowledge and expand their practice: The case of open education resources. British Journal of Educational Technology, 48, 2, 499-510. doi: https://doi.org/10.1111/bjet.12438

Ma, Q. (2016). An evidence-based study of Hong-Kong university students' mobile-assisted language learning (MALL) experience. In A. Gimeno, M. Levy, F. Blin, \& D. Barr (Eds.), Sustainability and computer-assisted language learning. London: Bloomsbury.

Manfreda, K. L., \& Vehovar, V. (2008). Internet Surveys. In E. D. de Leeuw, J. J. Hox, \& D. A. Dillman (Eds.), International handbook of survey methodology, (pp. 264-284), Abingdon: Routledge. doi: https://doi.org/10.4324/9780203843123.ch14

Masterman, L., Wild, J., White, D., \& Manton, M. (2011, December). The impact of OER on teaching and learning in UK universities: Implications for learning design. In L. Cameron \& J. Dalziel (Eds.), Proceedings of the 6th international LAMS \& learning design conference 2011: Learning design for a changing world (pp. 135-144). Sydney: LAMS Foundation. doi:http://lamsfoundation.org/lams2011sydney/papers.htm

McAndrew, P., Santos, A., Lane, A., Godwin, S., Okada, A., Wilson, T., Connolly, T., Ferreira, G., Buckingham Shum, S., Bretts, J., \& Webb, R. (2009). Open learn research report 20062008. Milton Keynes: The Open University. Retrieved from http://oro.open.ac.uk/17513/ 1/Researchfinal_low.pdf

Meurers, D. (2015). Learner corpora and natural language processing. In S. Granger, G. Gilquin, \& F. Meunier (Eds.), The Cambridge handbook of learner corpus research (pp. 535-536). Cambridge: Cambridge University Press. doi:10.1017/CBO9781139649414.024

Mishra, S., Sharma, M., Sharma, R., Singh, A., \& Thakur, A. (2016). Development of a scale to measure faculty attitude towards open educational resources. Open Praxis, 8, 1, 55-69. doi:https://doi.org/10.5944/openpraxis.8.1.236

Massachussets Institute of Technology . (2006). 2005 Program evaluation findings report. Retrieved from http://ocw.mit.edu/NR/rdonlyres/FA49E066-B838-4985-B548-F85C40B538B8/0/ 05_Prog_Eval_Report_Final.pdf

Massachussets Institute of Technology . (2009). 2009 Program evaluation findings report. Retrieved from www.ocw.mit.edu/ans7870/global/09_Eval_Summary.pdf

Murphy, P., \& Wolfenden, F. (2013). Developing a pedagogy of mutuality in a capability approach: Teachers' experiences of using the Open Educational Resources (OER) of the teacher education in sub-Saharan Africa (TESSA) programme. International Journal of Educational Development, 33, 263-271. doi:https://doi.org/10.1016/j.ijedudev.2012.09.010

Nagata, N. (2013). An effective application of natural language processing in second language instruction. CALICO Journal, 13, 1, 47-67. Retrieved 3 June, 2017, fromhttps://journals. equinoxpub.com/index.php/CALICO/article/view/23405

Naismith, L. (2004). Literature review in mobile technologies and learning. Bristol: NESTA Futurelab.

Nilsson, N. (2009). Natural language processing. In N. Nilsson (Ed.) The quest for artificial intelligence (pp. 103-113). Cambridge: Cambridge University Press. doi:10.1017/ CBO9780511819346.009

Owen, C. (2017). Surveys. In J. Swain (Ed.), Designing research in education (1st ed.) (pp. 123-147). London: Sage.

Page, T. (2014). Application-based mobile devices in design education. IJMLO, 8, 2, 96-111. doi:https://doi.org/10.1504/ijmlo.2014.062347

Pegrum, M. (2016). Language and literacies for digital lives. In E. Martín-Monje, I. Elorza, \& B. García Riaza (Eds.), Technology-enhanced language learning for specialized domains: Practical applications and mobility, (pp. 9-22), Abingdon: Routledge. 
Pérez-Paredes, P. (2010). Corpus linguistics and language education in perspective: Appropriation and the possibilities scenario, T. Harris, \& M. Moreno Jaén. In Corpus linguistics in language teaching (pp. 53-73). Bern: Peter Lang.

Pérez-Paredes, P., Sánchez-Tornel, M., \& Calero, J.M. A. (2012). Learners' search patterns during corpus-based focus-on-form activities: A study on hands-on concordancing. International Journal of Corpus Linguistics, 17, 482-515.

Petrides, L., Jimes, C., Middleton-Detzner, C., \& Howell, H. (2010, September). OER as a model for enhanced teaching and learning. Open ED 2010 proceedings. Barcelona: UOC, OU, BYU. Retrieved 17 March, 2016, fromhttp://hdl.handle.net/10609/4995

Petrides, L., Nguyen, L., Jimes, C., \& Karaglani, A. (2008). Open Educational Resources: Inquiring into author use and reuse. International Journal of Enhanced Learning, 1(1/2), 98-117.

Quan, Z. (2016). Introducing “mobile DDL (data-driven learning)” for vocabulary learning: An experiment for academic English. Journal of Computers in Education, 3, 273-287.

Rödel, B. (2013), BIBB/Open Educational Resources. Retrieved 29 February, 2016, fromhttps://www.bibb.de/en/22627.php

Rolfe, V. (2012). Open educational resources: Staff attitudes and awareness. Research in Learning Technology, 20, 1-13. doi:https://doi.org/10.3402/rlt.v20i0/14395

Romero, M., Pérez-Mateo, M., Cabrera, N., Guitert, M., \& Maina, M.. (2015). Regional analysis report open university of Catalo nia, Spain. Open University of Catalonia (UOC) . Retrieved from https://www.oerup.eu/fileadmin/_oerup/dokumente/need_analysis_report_UOC_Spain. doc

Sabadie, J., Muñoz, J., Punie, Y., Redecker, C., \& Vuorikari, R. (2014). OER: A European policy perspective. Journal of Interactive Media in Education, 2014, 1-12. doi:https://doi.org/ $10.5334 / 2014-05$

Sato, T., Matsunuma, M., \& Suzuki, A. (2013). Enhancement of automatization through vocabulary learning using CALL: Can prompt language processing lead to better comprehension in L2 reading ? ReCALL, 25, 143-158. doi:10.1017/S0958344012000328

Shin, D., Shin, Y., Choo, H., \& Beom, K. (2011). Smartphones as smart pedagogical tools: Implications for smartphones as u-learning devices. Computers in Human Behavior, 27, 2207-2214. doi:https://doi.org/10.1016/j.chb.2011.06.017

Steel, C. (2016). Students' perspectives on the affordances and constraints of using mobile devices and applications for learning languages. In A. Gimeno, M. Levy, F. Blin, \& D. Barr (Eds.), Sustainability and computer-assisted language learning. London: Bloomsbury.

Stockwell, G. (2010). Using mobile phones for vocabulary activities: Examining the effect on the platform. Language Learning \& Technology, 14, 95-110.

Sun, Y.-C., \& Wang, L.-Y. (2003). Concordancers in the EFL classroom: Cognitive approaches and collocation difficulty. Computer Assisted Language Learning, 16, 83-94.

Talai, T., \& Fotovatnia, Z. (2012). Data-driven learning: A student-centered technique for language learning. Theory and Practice in Language Studies, 2, 1526-1531. Retrieved fromhttps://search.proquest.com/docview/1346760757? accountid=9851

Thomas, M., \& Evans, M. (2014). Guest editorial. Computer Assisted Language Learning, 27, 107-108. doi:https://doi.org/10.1080/09588221.2014.874101

Traxler, J. (2005, June). Defining mobile learning. Proceedings of the IADIS international conference on mobile learning.IADIS, Qawra, Malta.

Traxler, J., \& Kukulska-Hulme, A. (Eds.). (2016). Mobile learning: The next generation. London: Routledge.

United Nations Educational, Scientific and Cultural Organization. (2012). What are open educational resources (OERs)?, Paris: Unesco.org. Retrieved 28 March, 2016, from 
http://www.unesco.org/new/en/communication-and-information/access-to-knowledge/ open-educational-resources/what-are-open-educational-resources-oers/

Wenk, B. (2010, April). Open educational resources (OER) inspire teaching and learning. Proceedings of the IEEE EDUCON education engineering 2010 - the future of global learning engineering education (pp. 435-442). Madrid: IEEE.

Wild, J. (2012). OER engagement study: Promoting OER reuse among academics (SCORE Fellowship Final Report). Oxford: University of Oxford and The Open University. Retrieved from http://www.open.ac.uk/score/files/score/file/Joanna\%20Wild\%20SCORE\%20Fellowship\% 20Final\%20Report\%20-\%20web\%20version.pdf,

Wiley, D., \& Henson, H. (2006, June). An initial characterization of engagement in informal social learning around MIT OCW.Proceedings of the 7th international conference on learning sciences (pp. 832-837). Bloomington, Indiana: ICLS. ISBN: 0-8058-6174-2.

Wiley, D., Hilton, J., Ellington, S., \& Hall, T. (2012). A preliminary examination of the cost savings and learning impacts of using open textbooks in middle and high school science classes. International Review of Research in Open and Distance Learning, 13, 3, 262-276.

Yeung, A., Taylor, P., Hui, C., Lam-Chiang, A., \& Low, E. (2011). Mandatory use of technology in teaching: Who cares and so what ? British Journal of Educational Technology, 43, 859-870. doi:https://doi.org/10.1111/j.1467-8535.2011.01253.x

Yoon, H., \& Jo, J. W. (2014). Direct and indirect access to corpora: An exploratory case study comparing students' error correction and learning strategy use in L2 writing. Language Learning \& Technology, 18, 96-117.

\section{Appendices}

\section{Appendix 1. Mann-Whitney $U$ tests for teachers' workplace and familiarity and frequency of use of MD and OERs}

\begin{tabular}{lcc} 
& Higher education vs. & \\
& secondary education & $p$ \\
\hline Frequency of use of mobile devices & $3,232.000$ & .414 \\
Frequency of use of OERs & 653.500 & .846 \\
Frequency of use of OERs in teaching & 571.000 & .399 \\
Familiarity with language learning apps & 735.500 & .815 \\
Familiarity with online dictionaries & $603.000^{*}$ & .037 \\
Familiarity with collocation dictionaries & $4915^{* *}$ & .001 \\
Familiarity with text-to-speech & 720.000 & .948 \\
Familiarity with text summarization tools & $5585^{*}$ & .115 \\
Familiarity with use of Wordnet & $529^{*}$ & .296 \\
Familiarity with visual representation of Word clusters tools & 620.000 & .554 \\
Familiarity with Word lists & $5125^{*}$ & .031 \\
Familiarity with lemmatizers & $485^{* *}$ & .001 \\
Familiarity with POS taggers & $5215^{* *}$ & .004 \\
Familiarity with vocabulary profilers & $4905^{* *}$ & .001 \\
Familiarity with spell checkers & 661.500 & .443 \\
Familiarity with readability indexes & $476^{* * *}$ & .002 \\
Familiarity with L1 corpora & $2585^{* * *}$ & .001 \\
Familiarity with specialized corpora & $3155^{* * *}$ & .001 \\
Familiarity with learner corpora & $337^{* * *}$ & .001 \\
Familiarity with corpus management tools & $383^{* * *}$ & .001 \\
Frequency of use of language learning apps & 665.000 & .991 \\
Frequency of use of online dictionaries & 598.000 & .181 \\
Frequency of use of collocation dictionaries & 642.500 & .100 \\
Frequency of use of text-to-speech & 721.500 & .456 \\
Frequency of use of text summarization tools & 698.500 & .154 \\
Frequency of use of Wordnet & 632.000 & .448 \\
& & $(c o n t i n u e d)$
\end{tabular}




\begin{tabular}{lcc}
\hline & $\begin{array}{c}\text { Higher education vs. } \\
\text { secondary education }\end{array}$ & $p$ \\
\hline Frequency of use of visual representation of Word clusters tools & 668.500 & .385 \\
Frequency of use of Word lists & 661.500 & .575 \\
Frequency of use of lemmatizers & 698.500 & .571 \\
Frequency of use of POS taggers & 723.500 & .704 \\
Frequency of use of vocabulary profilers & 689.000 & .452 \\
Frequency of use of spell checkers & 671.500 & .620 \\
Frequency of use of readability indexes & 732.500 & .676 \\
Frequency of use of L1 corpora & $498^{* *}$ & .017 \\
Frequency of use of specialized corpora & $5585^{*}$ & .021 \\
Frequency of use of learner corpora & 627.500 & .251 \\
Frequency of use of corpus management tools & 658.500 & .277 \\
\hline
\end{tabular}

\section{Appendix 2. Differences between teachers' qualification and familiarity and frequency of use of MD and OERs}

\begin{tabular}{|c|c|c|c|c|c|c|}
\hline & $\begin{array}{c}\text { BA } \\
\text { (mean) }\end{array}$ & $\begin{array}{c}\text { MA } \\
\text { (mean) }\end{array}$ & $\begin{array}{l}\mathrm{PhD} \\
\text { (mean) }\end{array}$ & $\begin{array}{l}\text { Kruskal-Wallis } \\
\text { Htest }\end{array}$ & $p$ & $\begin{array}{l}\text { Mann- } \\
\text { Whitney U test }\end{array}$ \\
\hline Frequency of use of mobile devices & 2.70 & 2.58 & 2.97 & 2.859 & .414 & \\
\hline Frequency of use of OERs & 2.44 & 2.79 & 2.62 & 0.816 & .846 & \\
\hline Frequency of use OERs in teaching & 2.04 & 2.45 & 2.64 & 2.952 & .399 & \\
\hline $\begin{array}{l}\text { Familiarity with language learning } \\
\text { apps }\end{array}$ & 2.85 & 2.70 & 2.67 & 0.942 & .815 & \\
\hline Familiarity with online dictionaries & 4.04 & 4.30 & 4.60 & $8.465^{*}$ & .037 & $\begin{array}{c}(\mathrm{BA}-\mathrm{PhD}) \\
U=-17.750\end{array}$ \\
\hline $\begin{array}{l}\text { Familiarity with collocation } \\
\text { dictionaries }\end{array}$ & 3.15 & 3.21 & 4.05 & $16.446^{* * *}$ & .001 & $\begin{array}{c}p=.020 \\
\text { (MA-PhD) } \\
U=-20.345 \\
p=.006 \\
(\mathrm{BA}-\mathrm{PhD}) \\
U=-19.368 \\
p=.018\end{array}$ \\
\hline Familiarity with text-to-speech & 2.15 & 2.12 & 2.31 & 0.363 & .948 & \\
\hline $\begin{array}{l}\text { Familiarity with text summarization } \\
\text { tools }\end{array}$ & 1.44 & 1.27 & 1.71 & 5.931 & .115 & \\
\hline Familiarity with use of Wordnet & 1.52 & 1.52 & 1.83 & 3.701 & .296 & \\
\hline $\begin{array}{l}\text { Familiarity with visual representation } \\
\text { of Word clusters tools }\end{array}$ & 1.78 & 2.15 & 2.00 & 2.089 & .554 & \\
\hline Familiarity with word lists & 1.56 & 1.94 & 2.33 & $8.861^{*}$ & .031 & $\begin{array}{c}(\mathrm{BA}-\mathrm{PhD}) \\
U=-20.250 \\
p=.010\end{array}$ \\
\hline Familiarity with lemmatizers & 1.07 & 1.33 & 1.88 & $17.432^{* * *}$ & .001 & $\begin{array}{c}(\mathrm{BA}-\mathrm{PhD}) \\
U=-24.626 \\
p=.001\end{array}$ \\
\hline Familiarity with POS taggers & 1.15 & 1.36 & 1.62 & $13.245^{* *}$ & .004 & $\begin{array}{c}(\mathrm{BA}-\mathrm{PhD}) \\
U=-19.590 \\
p=.003\end{array}$ \\
\hline Familiarity with vocabulary profilers & 1.07 & 1.88 & 1.71 & $16.692^{* * *}$ & .001 & $\begin{array}{c}\text { (BA-MA) } \\
U=-24.327 \\
p=.001 \\
(\mathrm{BA}-\mathrm{PhD}) \\
U=-22.892 \\
p=.001\end{array}$ \\
\hline Familiarity with spell checkers & 2.67 & 2.85 & 3.10 & 2.683 & .443 & \\
\hline Familiarity with readability indexes & 1.19 & 1.55 & 1.69 & $14.960^{* *}$ & .002 & $\begin{array}{c}(\mathrm{BA}-\mathrm{PhD}) \\
U=-23.253 \\
p=.001\end{array}$ \\
\hline
\end{tabular}




\begin{tabular}{|c|c|c|c|c|c|c|}
\hline & $\begin{array}{c}\mathrm{BA} \\
\text { (mean) }\end{array}$ & $\begin{array}{c}\mathrm{MA} \\
\text { (mean) }\end{array}$ & $\begin{array}{l}\mathrm{PhD} \\
\text { (mean) }\end{array}$ & $\begin{array}{c}\text { Kruskal-Wallis } \\
\text { Htest }\end{array}$ & $p$ & $\begin{array}{l}\text { Mann- } \\
\text { Whitney U test }\end{array}$ \\
\hline Familiarity with L1 corpora & 1.37 & 2.27 & 2.83 & $26.662^{* * *}$ & .000 & $\begin{array}{c}(\mathrm{BA}-\mathrm{MA}) \\
U=-21.709 \\
p=.010 \\
(\mathrm{BA}-\mathrm{PhD}) \\
U=-35.112 \\
p=.001\end{array}$ \\
\hline Familiarity with specialized corpora & 1.33 & 1.88 & 2.62 & $27.093^{* * *}$ & .000 & $\begin{array}{c}(\mathrm{BA}-\mathrm{PhD}) \\
U=-33.664 \\
p=.001 \\
(\mathrm{MA}-\mathrm{PhD}) \\
U=-19.556 \\
p=.008\end{array}$ \\
\hline Familiarity with learner corpora & 1.33 & 1.76 & 2.36 & $20.946^{* * *}$ & .000 & $\begin{array}{c}(\mathrm{BA}-\mathrm{PhD}) \\
U=-28.824 \\
p=.001\end{array}$ \\
\hline $\begin{array}{l}\text { Familiarity with corpus management } \\
\text { tools }\end{array}$ & 1.15 & 1.52 & 2.12 & $23.373^{* * *}$ & .000 & $\begin{array}{c}(\mathrm{BA}-\mathrm{PhD}) \\
U=-30.608 . \\
p=.001 \\
(\mathrm{MA}-\mathrm{PhD}) \\
U=-16.605 \\
p=.018\end{array}$ \\
\hline $\begin{array}{l}\text { Frequency of use of language } \\
\text { learning apps }\end{array}$ & 2.11 & 1.97 & 1.95 & 0.107 & .991 & \\
\hline $\begin{array}{l}\text { Frequency of use of online } \\
\text { dictionaries }\end{array}$ & 3.52 & 3.55 & 3.93 & 4.875 & .181 & \\
\hline $\begin{array}{l}\text { Frequency of use of collocation } \\
\text { dictionaries }\end{array}$ & 2.70 & 2.30 & 3.12 & 6.255 & .100 & \\
\hline Frequency of use of text-to-speech & 1.30 & 1.48 & 1.64 & 2.606 & .456 & \\
\hline $\begin{array}{l}\text { Frequency of use of text } \\
\text { summarization tools }\end{array}$ & 1.15 & 1.12 & 1.29 & 5.255 & .154 & \\
\hline Frequency of use of Wordnet & 1.22 & 1.21 & 1.48 & 2.653 & .448 & \\
\hline $\begin{array}{l}\text { Frequency of use of visual } \\
\text { representation of Word clusters } \\
\text { tools }\end{array}$ & 1.26 & 1.36 & 1.57 & 3.040 & .385 & \\
\hline Frequency of use of word Lists & 1.26 & 1.36 & 1.60 & 1.988 & .575 & \\
\hline Frequency of use of lemmatizers & 1.15 & 1.12 & 1.21 & 2.004 & .571 & \\
\hline Frequency of use of POS taggers & 1.15 & 1.09 & 1.17 & 1.406 & .704 & \\
\hline $\begin{array}{l}\text { Frequency of use of vocabulary } \\
\text { profilers }\end{array}$ & 1.11 & 1.36 & 1.29 & 2.632 & .452 & \\
\hline Frequency of use of spell checkers & 1.81 & 1.91 & 2.21 & 1.778 & .620 & \\
\hline $\begin{array}{l}\text { Frequency of use of readability } \\
\text { indexes }\end{array}$ & 1.19 & 1.24 & 1.19 & 1.525 & 676 & \\
\hline Frequency of use of L1 corpora & 1.11 & 1.45 & 1.81 & $10.235^{*}$ & .017 & $\begin{array}{c}(\mathrm{BA}-\mathrm{PhD}) \\
U=-17.750 . \\
p=.020\end{array}$ \\
\hline $\begin{array}{l}\text { Frequency of use of specialized } \\
\text { corpora }\end{array}$ & 1.15 & 1.27 & 1.76 & $9.756^{*}$ & .021 & $\begin{array}{c}(\mathrm{BA}-\mathrm{PhD}) \\
U=-15.799 \\
p=.014\end{array}$ \\
\hline Frequency of use of learner corpora & 1.15 & 1.21 & 1.55 & 4.096 & .251 & \\
\hline $\begin{array}{l}\text { Frequency of use of corpus } \\
\text { management tools }\end{array}$ & 1.11 & 1.12 & 1.29 & 3.857 & .277 & \\
\hline
\end{tabular}

Note: Differences between teachers' qualification and familiarity and frequency of use of MD and OERs.

${ }^{*} \mathrm{p}<.05 ;{ }^{* *} \mathrm{p}<.01 ;{ }^{* * *} \mathrm{p}<.001$ 